\title{
Responsabilidad del propietario y/0 arrendador de locales comerciales por contribuir o facilitar infracciones y delitos contra la propiedad industrial
}

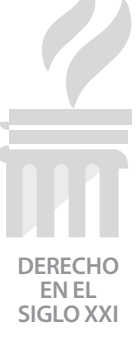

Adriana BarRera TABOAdA

Abogada por la Universidad de Lima. Maestría en Derecho de Propiedad Intelectual por Franklin Pierce Law Center.

SUMARIO:

I. Introducción.

II. Falsificación de productos o mercancías en la normativa peruana.

III. Responsabilidad de infractores indirectos: propietario/arrendador.

IV. Jurisprudencia comparada sobre responsabilidad del propietario/arrendador.

V. Responsabilidad del propietario/arrendador según normativa peruana.

1. Disposiciones sobre incumplimiento del contrato de arrendamiento.

2. Consideraciones sobre responsabilidad extracontractual del arrendador.

3. Normativa sobre propiedad industrial que puede ser aplicable a la responsabilidad del arrendador.

VI. Conclusiones. 


\title{
RESUMEN:
}

La falsificación y piratería constituyen problemas graves en la sociedad actual. Normalmente se responsabiliza a los actores e infractores directos sobre las violaciones a los derechos de propiedad industrial y derechos de autor, pero existen terceros 0 actores indirectos a quienes se les puede imputar responsabilidad por estos comportamientos ilegales que afectan el normal desenvolvimiento del comercio en el mercado.

Palabras clave: propiedad industrial, derechos de autor, infracciones, delitos, responsabilidad, terceros.

\begin{abstract}
:
Counterfeiting and piracy are serious problems in today's society. Normally, direct actors and infringers are held responsible for violations of industrial property rights and copyrights, but there are third parties or indirect actors who can be held responsible for these illegal behaviors that affect the normal development of trade in the market.

Keywords: industrial property, copyrights, infringements, crimes, liability, third parties.
\end{abstract}

\section{INTRODUCCIÓN}

En un mercado globalizado como el actual, la falsificación y la piratería de productos aumentan día a día y se hace cada vez más complicado combatirlas. Es claramente un problema global que se ha ido sofisticando; toda vez que los infractores de los derechos de propiedad industrial y derechos de autor buscan y encuentran nuevos mecanismos para violentar las reglas que regulan la propiedad intelectual. Lamentablemente, muchas veces se consideran a las infracciones y/o delitos contra la propiedad intelectual como de menor importancia o envergadura, cuando realmente muchas veces nos encontramos frente a la concurrencia de delitos, tales como: evasión de impuestos, lavado de dinero, explotación de personas y trabajo de menores, salud pública, entre otros. Por ello, los titulares de los derechos de propiedad industrial y derechos de autor deben buscar soluciones legales creativas para contrarrestar el comportamiento ilegal de los falsificadores y piratas.

Una de las estrategias que se está aplicando a nivel mundial es responsabilizar a los infractores indirectos, es decir, las personas naturales o jurídicas que de alguna manera contribuyen para que se logre infringir o delinquir contra la propiedad intelectual. Por ejemplo, se podría responsabilizar a los propietarios y/o arrendadores de establecimientos comerciales donde se ofrecen productos falsificados $y / o$ pirateados, que muchas veces tienen conocimiento de estos hechos ilegales. Esta teoría de responsabilidad ha sido ampliamente desarrollada en el derecho anglosajón y es conocida como contributory infringement ${ }^{1}$, Iandlord liability y vicarious liability. En Latinoamérica ya existen algunos países como Argentina y Brasil que han incluido esta teoría de responsabilidad en casos sobre infracciones y/o delitos contra la propiedad intelectual; sin embargo, es un desarrollo tímido. Lo mismo ocurre en nuestro país, donde no se ha desarrollado el tema ampliamente.

\section{FALSIFICACIÓN DE PRODUCTOS O MER- CANCÍAS EN LA NORMATIVA PERUANA}

Si bien la falsificación se refiere al uso no autorizado de marcas - propiedad industrial- y la piratería hace referencia a la copia de una obra protegida por los derechos de autor, ambos comportamientos están considerados como infracciones $y / o$ delitos contra la propiedad intelectual. Sin embargo, en esta oportunidad desarrollaremos el tema en relación a la violación de derechos de propiedad industrial; específicamente los derechos marcarios, y, por tanto, 
nos referiremos a falsificación de productos o mercancías.

Sobre la falsificación de productos, se conoce que toda fabricación, comercialización, distribución, almacenamiento de productos con signos idénticos y/o similares a marcas debidamente registradas sin contar con la debida autorización del titular constituye una infracción a los derechos de propiedad industrial, conforme lo establecido en el artículo 97 del Decreto Legislativo 1075, modificado por el Decreto Legislativo 1309; y los artículos 155 y 156 de la Decisión 486, Régimen Común sobre Propiedad Industrial de la Comunidad Andina -en adelante, la "Decisión"-, los cuales disponen lo siguiente:

\section{"Artículo 97.- Actos de infracción}

Constituyen actos de infracción todos aquellos que contravengan los derechos de propiedad industrial reconocidos en la legislación vigente y que se realicen o se puedan realizar dentro del territorio nacional.

La responsabilidad administrativa derivada de los actos de infracción a los derechos de propiedad industrial es objetiva."

"Artículo 155.- El registro de una marca confiere a su titular el derecho de impedir a cualquier tercero realizar, sin su consentimiento, los siguientes actos:

d) usar en el comercio un signo idéntico o similar a la marca respecto de cualesquiera productos o servicios, cuando tal uso pudiese causar confusión o un riesgo de asociación con el titular del registro. Tratándose del uso de un signo idéntico para productos o servicios idénticos se presumirá que existe riesgo de confusión;

\section{(...)."}

Asimismo, precisa la Decisión lo siguiente en relación al uso de un signo registrado por parte de un tercero en su artículo 156:
"Artículo 156.- A efectos de lo previsto en los literales e) y f) del artículo anterior, constituirán uso de un signo en el comercio por parte de un tercero, entre otros, los siguientes actos:

a) introducir en el comercio, vender, ofrecer en venta o distribuir productos o servicios con ese signo.

b) (...)

c) emplear el signo en publicidad, publicaciones, documentos comerciales o comunicaciones escritas $u$ orales, independientemente del medio de comunicación empleado y sin perjuicio de las normas sobre publicidad que fuesen aplicables."

Por otro lado, la conducta ilícita mencionada no solamente constituye una infracción en materia administrativa, sino que además constituye un delito, de acuerdo a lo establecido en el Código Penal peruano:

"Artículo 222.- Será reprimido con pena privativa de libertad no menor de dos ni mayor de cinco años, con sesenta a trescientos sesenta y cinco días multa e inhabilitación conforme al Artículo 36 inciso 4) tomando en consideración la gravedad del delito y el valor de los perjuicios ocasionados, quien en violación de las normas y derechos de propiedad industrial, almacene, fabrique, utilice con fines comerciales, oferte, distribuya, venda, importe o exporte, en todo o en parte:

\section{(...)}

f) Un producto o servicio que utilice una marca no registrada idéntica o similar a una marca registrada en el país."

\section{RESPONSABILIDAD DE INFRACTORES IN- DIRECTOS: PROPIETARIO/ARRENDADOR}

En tal sentido, los titulares de los derechos marcarios $u$ otros signos distintivos tienen la facultad de iniciar acciones legales contra los terceros responsables cuando consideren que sus derechos se vulneran.

Normalmente, las acciones tanto administrati-
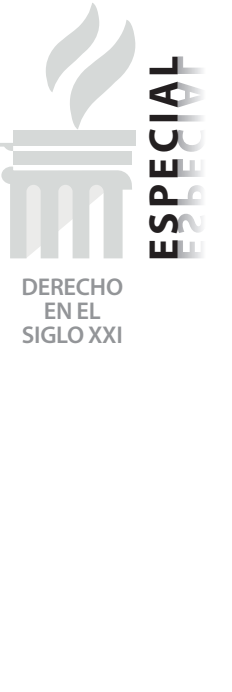
vas como penales se inician contra los responsables directos, que son los arrendatarios de los locales comerciales donde se viene constituyendo la infracción y/o delitos contra la propiedad industrial. Sin embargo, en el supuesto que el propietario y/o arrendador de un local comercial que tiene conocimiento que en el local comercial que arrienda se vienen comercializando productos falsificados - que infringen los derechos de propiedad industrial-, ¿se puede iniciar acciones legales contra el propietario/arrendador como responsable indirecto? ¿qué sucede con aquellos terceros que contribuyen con una infracción y/o delito?

En primer lugar, consideramos, que para responsabilizar al propietario/arrendador de un establecimiento, es importante que se pueda acreditar que el propietario/arrendador conocía o podía conocer de los hechos infractores y/o delictivos que viene realizando su arrendatario. Por tanto, el titular del derecho infringido antes de intentar involucrar al propietario/ arrendador en un proceso o procedimiento legal, debería asegurarse que el propietario/ arrendador tenía conocimiento del hecho infractor, ya sea porque ha sido informado o porque la infracción o delito es un hecho de público conocimiento.

Se considera que los casos más exitosos de responsabilidad del propietario/arrendador se han dado cuando se cumplen estos supuestos²:
a) La escala de la falsificación de los produc- tos en el mercado es severa;
b) Los productos falsificados son abiertamen- te comercializados;
c) El titular de la marca afectada — derecho de propiedad industrial - afectado sufre un daño significativo por los hechos ilegales;
d) El propietario/arrendador permanece pasi- vo o inactivo frente al problema.

Es así, que denunciar y responsabilizar al propietario/arrendador resulta más atractivo que denunciar únicamente al vendedor de los productos falsificados, ya que muchas veces el vendedor se puede mantener en el anonimato $y$, además, pueden tener menos bienes y/o activos que el propietario/arrendador.

En los casos que conocemos de otros países, que comentaremos más adelante, el supuesto que se debe cumplir es que el propietario/ arrendador conocía o debía conocer sobre la comercialización, distribución, fabricación o almacenamiento de productos falsificados por parte de su arrendatario y, que no hizo nada - o mínimo, omisión - para prevenir o detener estos actos ilegales.

Para tener un caso exitoso, y asegurarse que el propietario/arrendador conocía de los hechos infractores o delictivos, se sugiere que el titular de la marca le solicite al propietario/ arrendador, eventualmente antes de iniciar una acción, que cumpla con implementar ciertas medidas, a efectos de prevenir o detener la comisión de la infracción o delito, entre las cuales se mencionan ${ }^{3}$ :

a) Implementar medidas de control a modo de garantizar conocimiento pleno acerca de quiénes son los arrendatarios.

b) Incluir cláusulas resolutorias expresas dentro del contrato de arrendamiento que prohíban actividades relacionadas con productos falsificados y/o pirateados; otorgándoles las facultades como propietario del inmueble para desalojar a los arrendatarios en caso de utilizar el inmueble para realizar actividades ilícitas.

c) Mantener una política clara contra el uso del inmueble para cualquier tipo de acti-

2. Giay Gustavo y Andres O'Farrel, «Pursuing Landlords for Infringements. Wishful thinking or worthwhile remedies?», Revista World Trademark Review (diciembre 2015-enero 2016): 46-48.

3. Business Action to Stop Counterfeiting and Piracy —BASCAP_, Lineamientos Landlord Liability. 
vidad relacionada con la venta y/o fabricación de productos falsificados y/o pirateados. Tal política debe ser visible a través de avisos publicados en el establecimiento o la página web del centro comercial.

d) Realizar inspecciones periódicas de las tiendas y los puestos de los arrendatarios.

e) Contactarse con los titulares de los derechos de propiedad industrial infringido, en caso de observar actividades ilícitas que puedan vulnerar sus derechos.

\section{JURISPRUDENCIA COMPARADA SOBRE RESPONSABILIDAD DEL PROPIETARIO/ ARRENDADOR}

Como hemos señalado, la jurisprudencia anglosajona está más desarrollada en cuanto a la responsabilidad del intermediario/facilitador o propietario/arrendador del establecimiento donde se cometen infracciones a los derechos de propiedad intelectual. Sin embargo, queremos comentar dos casos en Brasil y Argentina, donde las cortes de dichos países responsabilizaron a los propietarios/arrendadores de los establecimientos.

El primer caso fue resuelto en el 2012 por la Corte de Justicia del Estado de São Paulo, Brasil, que fue iniciado por las empresas de denunciantes Nike Do Brasil Comércio E Participações Ltda., Nike International Ltda., Lvmh Fashion Group Brasil Ltda., Louis Vuitton Malletier, Oakley Brasil Ltda. y Oakley Incorporation contra Calinda Administração Participação E Comércio Ltda en adelante "Calinda"-, administrador y promotor del Centro Comercial 25 de Marzo de São
Paulo ${ }^{4}$. La Corte resolvió que Calinda debería prevenir que se comercialice, ofrezca en venta, o almacene productos falsificados en el Centro Comercial 25 de Marzo, con las marcas de las empresas denunciantes, bajo apercibimiento de pagar una multa diaria de $R \$ 31,000$ reales —aproximadamente S/ 20,800.005 - en caso no cumpla con prevenir el comportamiento ilegal de los comerciantes, toda vez que Calinda, administrador del centro comercial en mención, alquilaba los espacios y stands según contrato de arrendamiento existente $y$, por tanto, la Corte señaló que Calinda habría actuado por omisión por no prevenir la venta de productos falsificados y de contrabando con marcas reconocidas; más aún, que en diversas oportunidades se han realizado operativos para decomisar productos ilegales. Asimismo, Calinda debía pagar a las empresas denunciantes, titulares de las marcas reconocidas Oakley, Louis Vuitton y Nike el monto de R\$31,000 por concepto de daño moral.

Dos casos resueltos en Argentina: (a) caso "Galería La Morocha"6 mediante el cual, en el 2014, el Ministerio Público de la ciudad de Buenos Aires responsabiliza al administrador de la galería; $y$, (b) otro reciente: "Asociación Mutual de Vendedores Ambulantes de Retiro"7 resuelto por la Cámara Criminal y Correccional Federal - Sala 2. Ambos responsabilizan al administrador/arrendador de los locales comerciales donde se ofrecían, almacenaban mercadería falsificada.

En el caso "Galería La Morocha", lugar de acopio y depósito de mercancías y productos falsificados, se responsabilizó en un proceso penal a Enrique Adolfo Mora como partícipe necesario, imponiéndosele una multa de $\$ 30,000$ pesos argenti-

4. Sentencia de la Corte de Justicia del Estado de São Paulo, Brasil, apelación N 502.136.4/5-00, año 2012.

5. Al tipo de cambio del 10 de noviembre del 2020.

6. Investigación del Ministerio Público Fiscal de la Ciudad Autónoma de Buenos Aires, Unidad Coordinadora de Investigaciones Complejas-UCIC, 27 de noviembre de 2014.

7. Sentencia de la Cámara Criminal y Correccional Federal - Sala 2, CFP N 6869/2013/4/CA2, Poder Judicial de la Nación, Argentina, 27 de febrero de 2019. 
nos ARS —aproximadamente $S / 1,370.00^{8}$ — ser la persona encargada de administrar y cobrar los arrendamientos de los comerciantes en dicha galería, tomándose en cuenta que claramente Enrique Adolfo Mora conocía los hechos de venta ilegal de productos que se realizaba en el lugar.

En el segundo caso argentino, recientemente resuelto en febrero de 2019, la Corte señaló que en el centro comercial denominado "Centro de Compras" se había realizado diversas intervenciones de allanamiento para decomisar productos falsificados, tales como zapatillas e indumentaria deportiva de marcas reconocidas, esto desde hace cinco años. Asimismo, de las investigaciones se tomó conocimiento que los administradores y arrendadores de estos puestos en el centro comercial era la "Asociación Mutual de Vendedores Ambulantes de Retiro". Por tanto, la Corte señaló que no podía pasar inadvertido que la mercadería apócrifa se encontraba exhibida para la venta al público en un predio compuesto por una gran galería comercial, circunstancia que conforma un contexto susceptible de causar confusión en los eventuales adquirentes de tales productos.

Además, al haberse realizado dos allanamientos previos en donde se procedió a la identificación de las personas que ponían a la venta los productos apócrifos y a los encargados del lugar - los partícipes- que conocían la situación, más aún cuando - como se vio- la actividad ilícita se perpetró en el tiempo incluso con los mismos involucrados. Es así, que la Corte responsabilizó a los representantes de "Asociación Mutual de Vendedores Ambulantes de Retiro" por actuar como administradores del local comercial en mención.

Finalmente, un caso de agosto de 2019, emitido por la Corte Federal de Apelaciones del Circuito
Décimo Primero de los Estados Unidos de América, en el caso seguido por Luxottica Group S.p.A contra Airport Mini Mall, Llc, y otros, ${ }^{9}$ por contribuir a infringir sus derechos de propiedad industrial. En el caso, diversos locales comerciales de Airport Mini Mall —un centro comercial de productos con descuentos- estaban vendiendo lentes falsificados con la marca Luxottica Group S.p.A. Por tanto, la Corte de Apelaciones falló responsabilizando al administrador/ arrendador de contribuir con la comisión de la infracción de las marcas reconocidas de la demandante.

Como se ha podido ver en los casos anteriores, tanto cortes civiles - los casos de Brasil y Estados Unidos de América- y penales - los casos de Argentina - han responsabilizado a los propietarios/administradores/arrendadores de los centros comerciales de los casos en cuestión. Si bien existe amplitud de regulación y normativa que puede aplicarse para un caso concreto, posiblemente la vía civil sea la más adecuada, sobre todo, para efectos del pago indemnizatorio por daños y perjuicios al titular de las marcas. Sin embargo, no se descarta la alternativa penal, que en varios de los países latinoamericanos, incluyendo Perú, no existe la responsabilidad penal de una persona jurídica, sino de sus representantes $y$, eventualmente esto sea negativo para efectos de obtener una reparación civil. Sin embargo, puede ser positiva si se quiere involucrar a las personas naturales, representantes de la persona jurídica, en un proceso penal.

\section{RESPONSABILIDAD DEL PROPIETARIO/ ARRENDADOR SEGÚN NORMATIVA PE- RUANA}

Actualmente, en Perú no existe jurisprudencia extensa sobre la responsabilidad del arrendador o de quien contribuye con la comisión de

8. Al tipo de cambio del 10 de noviembre del 2020.

9. Sentencia de la Corte Federal de Apelaciones del Circuito Décimo Primero de los Estados Unidos de América del 7 de agosto de 2019, Caso N 18-10157. 
una infracción y/o delito contra la propiedad industrial, que en el derecho anglosajón, según ya hemos señalado, se encuentra ampliamente desarrollado y se denomina landlord liability.

Sin embargo, consideramos que sí debería existir responsabilidad del arrendador por los actos ilícitos de su arrendatario desde el punto de vista de la normativa civil y administrativa; pero dejaremos de lado - en esta oportunidad-el análisis de una aplicación desde el punto de vista penal, según desarrollamos a continuación.

\section{Disposiciones sobre incumplimiento del contrato de arrendamiento.}

Al respecto, consideramos que el arrendador debería tomar conocimiento de los actos ilícitos que se vienen cometiendo en los locales de su propiedad, de las consecuencias legales que estos actos implican y de las obligaciones que mantienen sobre el control de sus arrendatarios, en cuanto al cumplimiento de las normas que protegen la propiedad intelectual y restringen la comercialización y distribución de productos infractores $u$ otros actos ilícitos.

Como es de conocimiento general, el contrato de arrendamiento es un acto jurídico y como tal, entre sus requisitos indispensables se encuentra el fin lícito. Esto significa que el objeto del arrendamiento en todo momento debe estar orientado a cumplir el ordenamiento legal y a evitar que se transgredan las normas vigentes.

El hecho de que el contrato de arrendamiento deba cumplir con un fin lícito implica que el desarrollo del mismo por ambas partes, arrendador y arrendatario, se debe dar dentro de lo previsto por las normas legales vigentes, entre ellas el Código Civil.

Así, dentro del contrato de arrendamiento de locales comerciales, lo normal y natural es que el arrendador vele porque dentro de su local, el arrendatario no desarrolle actividades prohibidas o que estén en contra del sistema legal vigente. En el caso de locales comerciales esto incluye, especialmente, actos reñidos contra las normas que regulan el mercado, tales como las regulaciones que prohíben la venta de productos que infrinjan derechos protegidos por las leyes sobre propiedad intelectual.

El inciso 7 del artículo 1681 del Código Civil expresamente prevé que el arrendatario está obligado a no hacer uso imprudente del bien o contrario al orden público o a las buenas costumbres; es decir, que el uso del bien debe ser acorde a ley y no debe transgredir el ordenamiento vigente, tal como es el caso de la normatividad que protege los derechos de propiedad intelectual.

En concordancia con la norma citada, el inciso 3 del artículo 1697 del Código Civil establece como causal de resolución del contrato que el arrendatario dé al bien destino diferente de aquel para el que se le concedió expresa o tácitamente, o permita algún acto contrario al orden público o a las buenas costumbres. Es claro y evidente que la venta de productos infractores y/o falsificados constituye un acto contrario a la ley y al orden público.

Asimismo, tal como establece el artículo II del Título Preliminar del Código Civil, la ley no ampara el ejercicio ni la omisión abusivos de un derecho. Ello significa que si bien es derecho del arrendador, como propietario del local, el explotar el bien percibiendo la renta mensual por la cual se ha contratado; también pesa sobre el arrendador la obligación de cautelar que el bien arrendado, es decir el local comercial, no sea utilizado para fines que no sean lícitos, tales como la distribución y venta de productos falsificados.

Nótese que la norma citada del Código Civil habla de ejercicio abusivo del Derecho tanto por acción como por omisión. Esto implica que dejar de controlar las actividades del arrendatario de suerte tal de que éste pueda ejercer actividades no acordes al sistema legal vigente, no es admitido por el Derecho y más bien el arrendador debe participar controlando tales actividades, sobre todo cuando la norma sobre arrendamiento prevé como posibilidad de resolución del contrato, en caso de que el arrendatario use el bien infringiendo la ley.

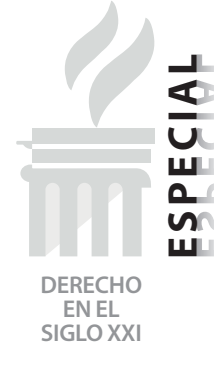




\section{Consideraciones sobre responsabilidad extracontractual del arrendador.}

Asimismo, el arrendador debe tomar en consideración que en el sistema legal peruano existe un régimen de responsabilidad civil. Este régimen está referido al aspecto fundamental de indemnizar los daños ocasionados en la relación de los particulares bien se trate de daños producidos como consecuencia del incumplimiento de una obligación voluntaria, principalmente contractual, o como resultado de una conducta, sin que exista entre los sujetos ningún vínculo de origen obligacional. Cuando el daño se produce sin que exista ninguna relación jurídica previa entre las partes, el daño es consecuencia, no del incumplimiento de una obligación voluntaria, sino simplemente del deber jurídico genérico de no causar un daño a otro, encontrándonos dentro del ámbito de la denominada responsabilidad civil extracontractual.

En el Perú, la norma básica de responsabilidad civil extracontractual está contenida en el artículo 1969 del Código Civil, complementada también por el artículo 1978 del mismo cuerpo legal:

\section{"Indemnización por daño moroso y culposo}

Artículo 1969.- Aquel que por dolo o culpa causa un daño a otro está obligado a indemnizarlo. El descargo por falta de dolo o culpa corresponde a su autor."

"Responsabilidad por incitación y/o coautoría
Artículo 1978.- También es responsable del daño aquel que incita o ayuda a causarlo. El grado de responsabilidad será determinado por el juez de acuerdo a las circunstancias."

Las normas citadas se refieren a que el autor del daño que se hubiera producido con o sin intención, debe resarcirlo reparando la situación del sujeto perjudicado. Así, casos en los cuales el arrendatario de un inmueble aprovecha dicho local para distribuir productos transgrediendo normas que protegen la propiedad intelectual, supone que el arrendador ha actuado con descuido y omisión en el cumplimiento de sus obligaciones dentro del sistema legal vigente.

\section{Normativa sobre propiedad industrial que puede ser aplicable a la responsabili- dad del arrendador.}

El Decreto Legislativo 1075 -que aprueba normas complementarias a la Decisión 486 de la Comunidad Andina-, recientemente modificado mediante el Decreto Legislativo $1397^{10}$, que incorpora el inciso e) al artículo $115^{11}$, regula las facultades de investigación de manera no taxativa que tendría la Comisión de Signos Distintivos del Instituto Nacional de Defensa de la Competencia y de la Protección de la Propiedad industrial —INDECOPI_-, en el sentido que se señala que podrá solicitar a una persona natural o jurídica, mediante el dictado de medidas cautelares o de una resolución que pone fin a una instancia, la adopción de medidas que sirvan para prevenir la ejecución o perpetración de actos realizados por terceros que cons-

10. Disposiciones Complementarias finales del Decreto Legislativo 1397 que modifica el Decreto Legislativo 1075, que aprueba Disposiciones Complementarias a la Decisión 486 de la Comisión de la Comunidad Andina que establece el Régimen Común sobre Propiedad Industrial.

11. Artículo 115.- Facultades de investigación

Sin que la presente enumeración tenga carácter taxativo, la autoridad nacional competente tiene las siguientes facultades de investigación:

(...)

e) Exigir, vía medida cautelar o resolución que ponga fin a la instancia, a las personas naturales o jurídicas, así como a entidades públicas o privadas, estatales o no estatales, con o sin fines de lucro, la adopción de medidas que impidan la continuación o perpetración de actos practicados por terceros que supongan el uso no autorizado de elementos protegidos por la propiedad industrial. 
tituyan el uso no autorizado de elementos de propiedad industrial.

Consideramos que mediante esta disposición se faculta a la Comisión de Signos Distintivos del INDECOPI para que pueda ahondar las investigaciones en casos de infracción a los derechos de propiedad industrial y en casos que lo considere necesario, para efectos de que cese la infracción podría ordenar a cualquier intermediario o tercero que contribuya con la infracción a tomar las medidas necesarias para evitar la comisión de infracciones contra la propiedad industrial, bajo la penalidad de imponer una sanción administrativa, que, eventualmente podría ser una multa o cierre de establecimiento -aunque creemos que esta segunda sería muy agresiva y es probable que la Comisión no se anime a aplicarla-, según establece la normativa administrativa dentro de sus sanciones. Es importante señalar que el intermediario no sería incluido como parte denunciada en el eventual procedimiento de infracción. Sin embargo, sí se podría ordenar al intermediario cumplir con lo ordenado por la Comisión, generándose una responsabilidad administrativa que, al no cumplirse, como ya señalamos tendría como consecuencia la imposición de una sanción administrativa únicamente.

En caso una medida cautelar o resolución por parte de la autoridad administrativa en este sentido, ordenada al intermediario/facilitador de la infracción, no sea cumplida por el mismo, podría ser utilizado, claramente, como prueba, en un eventual caso de daños y perjuicios donde se quiera acreditar la responsabilidad del facilitador o intermediario de la infracción para que pueda pagar por los daños y perjuicios causados al titular de los derechos de propiedad industrial por la omisión en el cumplimiento de la solicitud de colaboración y de las obligacio- nes que derivan del contrato de arrendamiento y extracontractuales, según lo hemos señalado en los puntos anteriores.

Si bien aún no existe jurisprudencia del INDECOPI donde se aplique de manera extensiva este artículo para considerar a los propietarios/ arrendadores como responsables, no debe descartarse la aplicación de este artículo en su inciso e) para facilitar la desarticulación de las redes de falsificadores de mercancías con marcas reconocidas, que tanto daño hacen a la economía interna y al comercio internacional.

\section{CONCLUSIONES}

Con una legislación clara que responsabilice a los propietarios y/o arrendadores de establecimientos, los titulares de las marcas tendrán un remedio claro y mayor predictibilidad a la hora de actuar, los gobiernos se verían beneficiados por la mayor eficacia de las acciones que se inicien y los consumidores estarían protegidos por el desarrollo de un comercio más legal y justo.12

Consideramos que debe responsabilizarse al propietario $y / o$ arrendador de un inmueble en la comisión de delitos contra la propiedad intelectual, siempre que se cumplan ciertos supuestos; siendo el principal que se pruebe que el propietario y/o arrendador conocía o tenía cómo conocer sobre los hechos infractores y/o delictivos que se vienen cometiendo en su inmueble. En esos casos es evidente la responsabilidad del propietario/arrendador y debería aplicarse la normativa administrativa sobre infracción marcaria y civil sobre responsabilidad extracontractual actual. Sin embargo, recomendamos, además, una modificación legislativa en la que claramente quede tipificado este ilícito como infracción administrativa y como delito penal.

12. María Laura Perna, «Responsabilidad del locador y piratería marcaria» (tesina, Universidad Austral, Maestría en Propiedad Intelectual, 2012-2013), 35. 